Palumbi, S. R. The Evolution Explosion: How Humans Cause Rapid Evolutionary Change (W. W. Norton, New York, 2001).

6. Sinervo, B., Svensson, E. \& Comendant, T. Density cycles and an offspring quantity and quality game driven by natural selection. Nature 406, 985-988 (2000).

7. Bohannan, B. J. M. \& Lenski, R. E. Linking genetic change to community evolution: Insights from studies of bacteria and bacteriophage. Ecol. Lett. 3, 362-377 (2000).

8. Abrams, P. A. The evolution of predator-prey interactions: theory and evidence. Annu. Rev. Ecol. Syst. 31, 79-105 (2000)

9. Shertzer, K. W., Ellner, S. P., Fussmann, G. F. \& Hairston, N. G. Jr Predator-prey cycles in an aquatic microcosm: Testing hypotheses of mechanism. J. Anim. Ecol. 71, 802-815 (2002).

10. Berryman, A. (ed.) Population Cycles: The Case for Trophic Interactions (Oxford Univ. Press, 2002).

11. Turchin, P. Complex Population Dynamics: A Theoretical/Empirical Synthesis (Princeton Univ. Press, 2003)

12. Pickett-Heaps, J. D. Green Algae: Structure, Reproduction and Evolution in Selected Genera (Sinauer Associates, Sunderland, Massachusetts, 1975).

13. Fussmann, G. F., Ellner, S. P., Shertzer, K. W. \& Hairston, N. G. Jr Crossing the Hopf bifurcation in a live predator-prey system. Science 290, 1358-1360 (2000).

14. Vermeij, G. J. Evolution and Escalation: An Ecological History of Life (Princeton Univ. Press, 1987). 15. Vermeij, G. J. The evolutionary interaction among species: selection, escalation, and coevolution. Annu. Rev. Ecol. Syst. 25, 219-236 (1994).

16. Tollrian, R. \& Harvell, C. D. (eds) The Ecology and Evolution of Inducible Defenses (Princeton Univ. Press, 1999).

17. Kendall, B. E. et al. Why do populations cycle? A synthesis of statistical and mechanistic modeling approaches. Ecology 80, 1789-1805 (1999).

18. Lambin, X., Krebs, C. J., Moss, R. \& Yoccoz, N. G. in Population Cycles: The Case for Trophic Interactions (ed. Berryman, A.) 155-176 (Oxford Univ. Press, 2002).

19. Hillborn, R. \& Mangel, M. The Ecological Detective: Confronting Models with Data (Princeton Univ. Press, 1997).

20. McCauley, E., Nisbet, R. M., Murdoch, W. W., de Roos, A. M. \& Gurney, W. S. C. Large-amplitude cycles of Daphnia and its algal prey in enriched environments. Nature 402, 653-656 (1999).

21. Turchin, P. et al. Dynamical effects of plant quality and parasitism on population cycles of larch budmoth. Ecology (in the press).

22. Halbach, U. \& Halbach-Keup, G. Quantitative relations between phytoplankton and the population dynamics of the rotifer Brachionus calyciflorus Pallas. Results of laboratory experiments and field studies. Arch. Hydrobiol. 73, 273-309 (1974).

23. Rothhaupt, K. O. Algal nutrient limitation affects rotifer growth rate but not ingestion rate. Limnol Oceanogr. 40, 1201-1208 (1995).

24. Monod, J. La technique de culture continue: theorie et applications. Ann. Inst. Pasteur Lille 79, 390-410 (1950).

25. Ihaka, R. \& Gentleman, R. R: a language for data analysis and graphics. J. Comp. Graph. Stat. 5, 299-314 (1996).

Supplementary Information accompanies the paper on www.nature.com/nature.

Acknowledgements We thank B. Kendall, K. Shertzer, J. Urabe and members of the EEB theoretical ecology 'lunch-bunch' for comments on the manuscript; A. Sasaki and C. Aquadro for discussions on clonal evolution; and M. Armsby, S. Hammer, M. Hung, C. Kearns, K. Keller and J. Meyer for assistance with the experiments. The study was supported by a grant from the Andrew W. Mellon Foundation to S.P.E. and N.G.H.

Competing interests statement The authors declare that they have no competing financial interests.

Correspondence and requests for materials should be addressed to N.G.H. (NGH1@cornell.edu).

\section{Complex hybrid origin of genetic caste determination in harvester ants}

\section{Sara Helms Cahan \& Laurent Keller}

Institute of Ecology, University of Lausanne, CH-1015 Lausanne, Switzerland

Caste differentiation and division of labour are the hallmarks of insect societies ${ }^{1}$ and at the root of their ecological success ${ }^{2}$. Kin selection predicts that caste determination should result from environmentally induced differences in gene expression ${ }^{3,4}$, a prediction largely supported by empirical data ${ }^{5}$. However, two exceptional cases of genetically determined caste differentiation have recently been found in harvester ants ${ }^{6-8}$. Here we show that genetic caste determination evolved in these populations after complex hybridization events. We identified four distinct genetic lineages, each consisting of unique blends of the genomes of the parental species, presumably Pogonomyrmex barbatus and $P$. rugosus. Crosses between lineages $\mathrm{H} 1$ and $\mathrm{H} 2$ and between $\mathrm{J} 1$ and $\mathrm{J} 2$ give rise to workers, whereas queens develop from withinlineage matings. Although historical gene flow is evident, genetic exchange among lineages and between lineages and the parental species no longer occurs. This unusual system of caste determination seems to be evolutionarily stable.

Pogonomyrmex barbatus and P. rugosus are common harvester ant species whose ranges broadly overlap in southwestern North America'. In both species, a population within the overlap zone in southwestern New Mexico has been found to possess a system of genetic caste determination ${ }^{6-8}$. By contrast, caste determination in populations outside the overlap zone is non-genetic ${ }^{7,8}$, as is typical in ants ${ }^{10}$

To gain insight into the origin of genetic caste determination and the relationship between its occurrences in the two species, we conducted a genetic study of the two adjacent sites (Hidalgo ${ }^{6}$ and Junction $^{7}$ ) in which genetic caste determination has been described, and also in allopatric populations of P. rugosus and P. barbatus (see Methods). The three classes of genetic markers (allozymes, microsatellites and mitochondrial sequence data) revealed that the two sites are each composed of a distinct pair of interbreeding lineages, H1 (red-male ${ }^{6}$ ) and H2 (black-male ${ }^{6}$ ) at Hidalgo, and J1 (lineage X (ref. 7)) and J2 (lineage 4 (ref. 7)) at Junction. Each lineage has a unique multilocus genotype (Table 1) and is strongly differentiated from all other lineages (Nei's $D$, range $=0.53-1.50$ ). Each lineage also contains a diagnostic monophyletic set of mitochondrial haplotypes (Fig. 1), showing a lack of genetic exchange across lineages.

As in previous studies ${ }^{6-8}$, there were marked differences in the genomic composition of queens and workers at both Hidalgo and Junction. Of the 42 winged (young) queens collected at Hidalgo, 40 contained either an $\mathrm{H} 1-\mathrm{H} 1$ or $\mathrm{H} 2-\mathrm{H} 2$ genome, the remaining two having $\mathrm{H} 1-\mathrm{H} 2$ genomes. All 40 workers had an $\mathrm{H} 1-\mathrm{H} 2$ genome. A similar pattern was uncovered at Junction. Of the 38 winged queens, 37 had a J1-J1 or J2-J2 genome while one queen and all 35 workers had J1-J2 genomes. The few inter-lineage winged queens produced seem to have low reproductive success; we found no colonies displaying genotypes consistent with an inter-lineage mother (queen) at these sites or at five other sites surveyed in the region (22-40 colonies sampled per site, S. Helms Cahan and L. Keller, unpublished observations). We also did not find a single individual with an H-J genome of any type (H1-J1, H1-J2, H2-J1 or H2-J2), indicating that crosses between lineages from the two sites either do not occur or fail to give rise to viable females.

In addition to being genetically isolated from one another, all four lineages are genetically distinct from the P. rugosus and P. barbatus populations with non-genetic caste determination. Genetic distances between each species and the four lineages were uniformly high (P. rugosus, 0.35-0.85; P. barbatus, 0.56-1.39), with diagnostic differences at one or more nuclear loci between the two species and each of the four lineages (see Supplementary Information). Haplotypes of all four lineages were also clearly differentiated from both $P$. rugosus and $P$. barbatus (Fig. 1). Thus, neither P. barbatus nor P. rugosus seems to be currently linked by gene flow with any of the four lineages.

Two general hypotheses have been proposed for the origin of a two-lineage genetic caste system. The first is that a heterozygositybased caste locus evolved within species, resulting in the splitting of the ancestral gene pool into two diverging lineages ${ }^{7}$. The second is that the evolution of genetic caste determination is associated with interspecific hybridization ${ }^{6,8}$. Our results show that the presence of distinct lineages within populations resulted from hybridization, most probably between P. rugosus and P. barbatus. Across nuclear markers, the two interbreeding lineages at each site clustered with different parental species: $\mathrm{H} 1$ and $\mathrm{J} 1$ with $P$. rugosus, and $\mathrm{H} 2$ and $\mathrm{J} 2$ with P. barbatus (Fig. 2). Moreover, the coxl mitochondrial haplotypes of $\mathrm{J} 1$ and $\mathrm{J} 2$ grouped together are paraphyletic (Fig. 1): the J1 clade is most closely related to P. rugosus, whereas that of $\mathrm{J} 2$ is 


\begin{tabular}{|c|c|c|c|c|c|c|c|c|c|c|c|}
\hline Locus & Allele & $\mathrm{H} 1$ & $\mathrm{H} 2$ & J1 & J2 & Locus & Allele & $\mathrm{H} 1$ & $\mathrm{H} 2$ & $\mathrm{J1}$ & $\sqrt{\mathrm{J} 2}$ \\
\hline \multirow[t]{6}{*}{ PGI } & 1 & - & - & 0.182 & - & $P b 5$ & 216 & - & 0.063 & - & 0.022 \\
\hline & 2 & - & - & 0.818 & - & & 222 & - & - & - & 0.022 \\
\hline & 3 & 1.000 & - & - & - & & 224 & - & 0.063 & - & 0.065 \\
\hline & 4 & - & 1.000 & - & 1.000 & & 226 & - & 0.875 & - & - \\
\hline & $n$ & 17 & 9 & 11 & 20 & & 228 & - & - & - & 0.087 \\
\hline & & & & & & & 232 & 1.000 & - & 0.591 & 0.696 \\
\hline \multirow[t]{4}{*}{ PGM-2 } & 1 & 1.000 & - & 1.000 & - & & 234 & - & - & - & 0.022 \\
\hline & 2 & - & 1.000 & - & 1.000 & & 236 & - & - & - & 0.087 \\
\hline & $n$ & 8 & 4 & 11 & 15 & & 240 & - & - & 0.045 & - \\
\hline & & & & & & & 242 & - & - & 0.318 & - \\
\hline \multirow[t]{4}{*}{ EST-2 } & 1 & - & 1.000 & 1.000 & 1.000 & & 244 & - & - & 0.045 & - \\
\hline & 2 & 1.000 & - & - & - & & $n$ & 24 & 8 & 11 & 23 \\
\hline & $n$ & 9 & 4 & 11 & 19 & & & & & & \\
\hline & & & & & & $P b 7$ & 139 & - & 0.071 & - & - \\
\hline \multirow[t]{6}{*}{ Myrt3 } & 180 & 1.000 & 1.000 & 0.682 & - & & 140 & - & 0.071 & - & - \\
\hline & 182 & - & - & - & 1.000 & & 143 & - & 0.786 & - & - \\
\hline & 188 & - & - & 0.227 & - & & 148 & & 0.071 & 0.042 & \\
\hline & 190 & - & - & 0.091 & - & & 152 & 0.563 & - & 0.125 & 0.024 \\
\hline & $n$ & 22 & 8 & 11 & 21 & & 154 & 0.063 & - & 0.625 & 0.476 \\
\hline & & & & & & & 156 & 0.375 & - & 0.167 & - \\
\hline \multirow[t]{24}{*}{ L18 } & 156 & - & - & - & 0.023 & & 158 & - & - & - & 0.024 \\
\hline & 158 & - & - & - & 0.023 & & 160 & - & - & 0.042 & - \\
\hline & 159 & - & - & - & 0.023 & & 162 & - & - & - & 0.048 \\
\hline & 161 & - & - & - & 0.182 & & 168 & - & - & - & 0.190 \\
\hline & 163 & - & - & - & 0.205 & & 172 & - & - & - & 0.048 \\
\hline & 164 & 0.289 & - & - & - & & 178 & - & - & - & 0.024 \\
\hline & 165 & - & 0.143 & - & 0.136 & & 182 & - & - & - & 0.048 \\
\hline & 166 & 0.158 & - & - & - & & 184 & - & - & - & 0.095 \\
\hline & 167 & - & 0.429 & - & 0.091 & & 186 & - & - & - & 0.024 \\
\hline & 168 & 0.368 & - & 0.200 & - & & $n$ & 24 & 7 & 12 & $\begin{array}{c}21 \\
21\end{array}$ \\
\hline & 169 & - & 0.143 & - & 0.227 & & & & & & \\
\hline & 170 & 0.132 & - & - & - & $P b 8$ & 268 & - & - & 0.292 & - \\
\hline & 171 & - & 0.071 & - & 0.091 & & 270 & - & - & 0.708 & - \\
\hline & 180 & - & - & 0.200 & - & & 276 & 0.340 & - & - & - \\
\hline & 181 & - & 0.071 & 0.050 & - & & 278 & 0.560 & - & - & 0.326 \\
\hline & 182 & - & - & 0.150 & - & & 280 & 0.060 & - & - & - \\
\hline & 184 & 0.026 & - & 0.050 & - & & 282 & 0.020 & 0.786 & _ & - \\
\hline & 185 & - & 0.071 & - & - & & 284 & - & 0.071 & - & 0.065 \\
\hline & 186 & 0.026 & - & 0.150 & - & & 286 & 0.020 & - & - & 0.261 \\
\hline & 187 & - & 0.071 & - & - & & 288 & - & - & - & 0.087 \\
\hline & 188 & - & - & 0.150 & - & & 290 & - & - & - & 0.196 \\
\hline & 192 & - & - & 0.050 & - & & 292 & - & 0.143 & - & 0.043 \\
\hline & $n$ & 19 & 7 & 10 & 22 & 317 & - & - & - & 0.022 & \\
\hline & & & & & & & $n$ & 25 & 7 & 12 & 23 \\
\hline
\end{tabular}

Allele frequencies were based on genotypes of a single winged queen from each colony. Allozyme alleles are numbered consecutively by order of migration on cellulose acetate gels; microsatellite allele numbers refer to allele size as measured on an ABI 377 automated sequencer. An additional three allozyme loci (PGM-1, EST-1, HEX) showed no fixed differences between any pair of lineages. Allele frequencies of the four lineages at these loci, as well as allele frequencies of $P$. rugosus and $P$. barbatus populations at all loci, are given in the Supplementary Information.

associated with $P$. barbatus (Interior Branch Test, branch length for $(\mathrm{J} 1$, P. rugosus $)(\mathrm{J} 2$, P. barbatus $)=0.047 \pm 0.011$ (s.e.m.), confidence probability $=1$ ).

Although lineages have an overall affinity with one of the two parental species, inspection of the genotypic data reveals a surprising amount of genetic mixing. On average, only 63\% (range 59-73) of the alleles in each lineage also occur in its putative parent.
However, when the alleles of both parental species are considered the percentage of alleles accounted for increases to 85\% (range 7196); indeed, all four lineages contain a unique mix of alleles specific to $P$. barbatus and alleles specific to $P$. rugosus at both the allozyme and microsatellite loci (Table 2), indicating hybrid ancestry. A small proportion of alleles were not found in either parent; these were virtually all (20 of 22) at highly polymorphic microsatellite loci

\begin{tabular}{|c|c|c|c|c|c|c|c|c|c|c|c|}
\hline \multirow{2}{*}{ Locus } & \multirow[b]{2}{*}{ Type } & \multirow[b]{2}{*}{ P. rugosus } & \multirow[b]{2}{*}{ P. barbatus } & \multicolumn{2}{|c|}{$\mathrm{H} 1$} & \multicolumn{2}{|c|}{$\mathrm{H} 2$} & \multicolumn{2}{|c|}{ J1 } & \multicolumn{2}{|c|}{$\mathrm{J} 2$} \\
\hline & & & & P.r. & P.b. & P.r. & P.b. & P.r. & P.b. & P.r. & P.b. \\
\hline PGI & Protein & 3 & 2 & 1 & - & - & 1 & 1 & - & - & 1 \\
\hline$P G M-1$ & Protein & 0 & 1 & - & 1 & - & - & - & - & - & 1 \\
\hline Est-1 & Protein & 1 & 2 & 1 & 1 & 1 & 1 & - & - & - & - \\
\hline HEX & Protein & 1 & 0 & 1 & - & 1 & - & - & - & - & - \\
\hline PGM-2 & Protein & 0 & 1 & - & - & - & 1 & - & - & - & 1 \\
\hline EST-2 & Protein & 1 & 1 & - & 1 & - & - & - & - & - & - \\
\hline Myrt3 & Microsatellite & 3 & 1 & 1 & - & 1 & - & 2 & - & - & 1 \\
\hline$L 18$ & Microsatellite & 10 & 12 & 4 & - & - & 3 & 3 & 2 & 1 & 5 \\
\hline Pb5 & Microsatellite & 7 & 8 & - & 1 & - & 1 & 3 & 1 & 1 & 4 \\
\hline$P b 7$ & Microsatellite & 12 & 3 & - & 2 & - & - & 3 & - & - & 2 \\
\hline$P b 8$ & Microsatellite & 3 & 6 & 1 & - & - & - & 1 & - & 1 & - \\
\hline Total $P$. rugosus alleles & & 41 & - & 9 & & 3 & & 9 & & 3 & \\
\hline Total $P$. barbatus alleles & & - & 37 & & 6 & & 7 & & 7 & & 15 \\
\hline
\end{tabular}




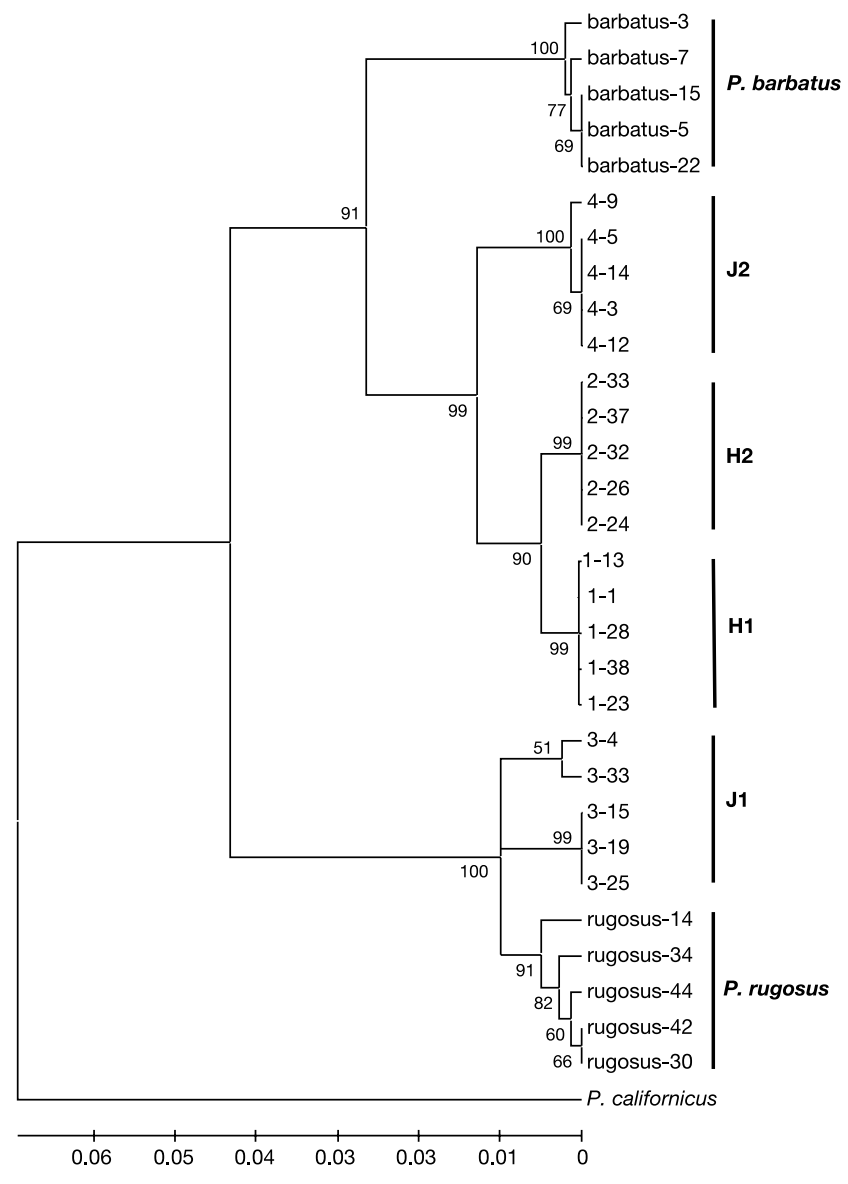

Figure 1 Linearized neighbour-joining tree of a 433-base-pair portion of the cox 1 mitochondrial gene in the two pairs of interbreeding lineages and populations of Pogonomyrmex barbatus and $P$. rugosus. The phylogeny generated with the Kimura twoparameter distance model (MEGA 2.1) is presented here; analyses with parsimony and maximum-likelihood methods produced the same topology. Numbers at the nodes indicate bootstrap percentages (500 replicates).

( $N_{\mathrm{a}}=18-35$ alleles) and might represent unsampled parental alleles or subsequent mutations. The pattern of allelic ancestry within lineages is also consistent with hybrid origin ${ }^{11,12}$. Admixture of the two species' genomes is particularly evident when comparing across loci; at any individual locus, lineages are often fixed for the allele of only one parent (Table 2 and Supplementary Information), as expected if initial polymorphisms have been lost within lineages owing to recombination and drift ${ }^{13}$. Thus, each of the four lineages forms a chimaeric genome, with a unique combination of the genes of the two parental species.

The chimaeric nature of the four lineages suggests a novel model for the evolution of genetic caste determination that could explain observed patterns of caste bias in both pure-lineage and interlineage offspring. In the simplest model, two loci $(A$ and $B)$, whose alleles differ between species ( $b$ is $P$. barbatus allele, $r$ is $P$. rugosus allele), must interact to initiate worker development, but only conspecific alleles can interact successfully. If a hybrid lineage were fixed for alleles of different species at the two loci (either $A_{b} A_{b} / B_{r} B_{r}$ or $A_{r} A_{r} / B_{b} B_{b}$ genotypes), pure-lineage females would be restricted to queen development. However, correct interlocus communication would be restored in double heterozygotes (inter-lineage crosses, $A_{b} A_{r} / B_{b} B_{r}$ ) because each allele has a conspecific partner with which to interact. Thus, females with an inter-lineage genome would be bipotential but almost always develop into workers because too many pure-lineage females committed to queen development are

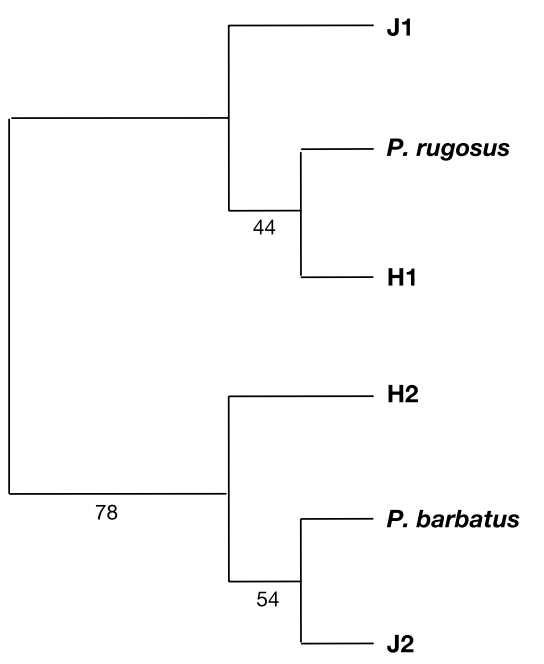

Figure 2 Maximum-likelihood consensus tree from the use of chord genetic distances ${ }^{20}$ calculated from nuclear markers (six allozymes and four microsatellites). The tree is unrooted and branch lengths are not illustrated. Numbers at nodes indicate bootstrap percentages (500 replicates).

already present within colonies.

Genotypic patterns found within field colonies are consistent with the gene interaction model. Not a single pure-lineage worker has been identified in this study $(n=75)$ or in other $^{6-8}$ studies, indicating an intrinsic breakdown in the worker caste trajectory of such offspring. Inter-lineage queens were extremely rare, both in this study ( $n=3$ of 80$)$ and in other studies ${ }^{6,8}$, and, as predicted, their occurrence seems highly dependent on the presence of purelineage offspring ${ }^{6}$. Production of inter-lineage winged queens is not distributed evenly across colonies but is restricted to certain colonies in which no pure-lineage winged queens have been observed (data for 13 colonies, 6 queens per colony; $G$ goodnessof-fit test, $G_{1}=6.67, P<0.01$ ). These are most probably colonies in which the queen has failed to mate with any same-lineage males ${ }^{6}$.

Our findings show that hybridization events between Pogonomyrmex species gave rise to an evolutionary novelty in which four unique hybrid lineages are linked in pairs by an unusual genetic system of caste determination. The current lack of gene flow between lineages, coupled with high levels of interbreeding, will apparently allow the system to persist indefinitely. More generally, these findings reveal a complex interaction between genetic and environmental factors in the expression of divergent caste phenotypes.

\section{Methods}

\section{Sampling}

A single queen and worker were sampled from a total of 76 colonies from the two populations in southwestern New Mexico, USA, where the interbreeding lineages were first described: Hidalgo ${ }^{6}$ and Junction $\left(\sim 2 \mathrm{~km}\right.$ south of the original P. barbatus site $\left.{ }^{7}\right)$.

These two sites are separated by $6 \mathrm{~km}$ of continuous habitat. Workers were also collected from 36 colonies from a $P$. barbatus population near Blumenthal, Travis County, Texas, $\sim 1,000 \mathrm{~km}$ ESE of Hidalgo and Junction, and from 44 colonies from a P. rugosus population in Pinal County, Arizona, $\sim 260 \mathrm{~km}$ northwest of the sites $\left(\right.$ Queen $\mathrm{Creek}^{6}$ ). No heterozygosity excess, indicative of genetic caste determination, was detected in workers in either of these populations (per-locus randomization tests: $P$. rugosus, $P_{\text {LOCUS }}=0.11-$ 1.00 ; . barbatus, $\left.P_{\text {LOCUS }}=0.35-1.00\right)$.

\section{Nuclear genotyping}

Allozyme protocols followed that in ref. 6. Enzyme data for 31 of the 42 Hidalgo P. rugosus colonies were previously presented in ref. 6; all other data are presented here. DNA was extracted from the alitrunk ( $=$ thorax) of individual ants with the Puregene tissue extraction kit (Gentra). DNA concentration was quantified in a Hoefer DyNA Quant 200 fluorimeter and diluted when necessary to achieve $10-30 \mu \mathrm{g} \mathrm{ml}^{-1}$ DNA. Five microsatellite loci, three designed specifically for P. barbatus ( $P b 5, P b 7$ and $P b 8)^{14}$ and two designed for other genera (Myrt3 (ref. 15) and L18 (ref. 16)), were amplified in 10- $\mu$ l 
reactions consisting of $1 \mu \mathrm{l}$ DNA, $1 \mu \mathrm{l}$ Qiagen $10 \times$ PCR buffer, $1 \mu \mathrm{l} 2 \mu \mathrm{M}$ dNTPs, $0.8 \mu \mathrm{l}$ $25 \mathrm{mM} \mathrm{MgCl}_{2}, 1 \mu \mathrm{l} 10 \mu \mathrm{M}$ fluorescently tagged forward and reverse primers, $0.05 \mu \mathrm{l}$ Qiagen Taq polymerase and $4.15 \mu \mathrm{l}$ sterile water. All loci were amplified with the following programme: $94^{\circ} \mathrm{C}$ for $4 \mathrm{~min}, 39$ cycles of $94^{\circ} \mathrm{C}$ for $30 \mathrm{~s}, 54^{\circ} \mathrm{C}$ or $57^{\circ} \mathrm{C}$ for $30 \mathrm{~s}$ and $72^{\circ} \mathrm{C}$ for $1.5 \mathrm{~min}$, then $72^{\circ} \mathrm{C}$ for $6 \mathrm{~min}$ and pausing at $4^{\circ} \mathrm{C}$. Loci were detected on an ABI 377 automatic sequencer.

A single winged queen was used from each colony at Hidalgo and Junction to determine allele frequencies. For most colonies ( 73 of 76 ), the multilocus genotype of the queen could be classified into one of four distinct classes or lineages (see the text). The exceptions all possessed genotypes consistent with an $\mathrm{F}_{1}$ hybrid between two lineages (heterozygous at all diagnostic loci); such queens were noted but excluded when calculating the allele frequencies of each lineage. Workers were used to calculate allele frequencies in the P. barbatus and $P$. rugosus populations.

\section{MtDNA sequencing}

We analysed a 433-base-pair portion of the mitochondrial gene coxl, encoding cytochrome oxidase $c$ subunit I. Pogonomyrmex californicus was used as the outgroup for the analysis; this species has been placed in a different complex within the genus ${ }^{17,18}$. DNA was sequenced from a single winged queen or worker for five colonies of each lineage (determined from nuclear genotype) and the two parental populations. Universal insect coxl primers (forward, C1-J-1751; reverse, C1-N-2191) were used ${ }^{19}$, except for the substitution of A for $\mathrm{C}$ at position 3 of $\mathrm{C} 1-\mathrm{N}-2191$. DNA was amplified in $50-\mu \mathrm{l}$ reactions $\left(5 \mu \mathrm{l}\right.$ DNA, $5 \mu$ l Qiagen $10 \times$ buffer, $4 \mu \mathrm{l} 25 \mathrm{mM} \mathrm{MgCl}_{2}, 5 \mu \mathrm{l} 10 \mu \mathrm{M}$ forward and reverse primers, $20.75 \mu \mathrm{l}$ water, $0.25 \mu \mathrm{l}$ Qiagen Taq polymerase) and amplified with the following PCR conditions: $94^{\circ} \mathrm{C}$ for $4 \mathrm{~min}, 35$ cycles of $94^{\circ} \mathrm{C}$ for $30 \mathrm{~s}, 48^{\circ} \mathrm{C}$ for $30 \mathrm{~s}$ and $72{ }^{\circ} \mathrm{C}$ for $1.5 \mathrm{~min}$, then $72^{\circ} \mathrm{C}$ for $6 \mathrm{~min}$ and pausing at $4{ }^{\circ} \mathrm{C}$. PCR products were purified with Qiaquick purification columns. Sequencing reactions and detection were performed by Microsynth $\mathrm{GmbH}$, Switzerland. Both forward and reverse strands were sequenced.

Received 3 February; accepted 6 May 2003; doi:10.1038/nature01744.

1. Wilson, E. O. The Insect Societies (Belknap, Cambridge, 1971).

2. Oster, G. F. \& Wilson, E. O. Caste and Ecology in the Social Insects (Princeton Univ. Press, 1978).

3. Crozier, R. H. \& Pamilo, P. Evolution of Social Insect Colonies: Sex Allocation and Kin Selection (Oxford Univ. Press, 1996).

4. Seger, J. Kinship and covariance. J. Theor. Biol. 91, 191-213 (1981).

5. Wheeler, D. E. Developmental and physiological determinants of caste in social Hymenopteraevolutionary implications. Am. Nat. 128, 13-34 (1986)

6. Helms Cahan, S. et al. Extreme genetic differences between queens and workers in hybridizing Pogonomyrmex harvester ants. Proc. R. Soc. Lond. B 269, 1871-1877 (2002).

7. Volny, V. P. \& Gordon, D. M. Genetic basis for queen-worker dimorphism in a social insect. Proc. Natl Acad. Sci. USA 99, 6108-6111 (2002).

8. Julian, G. E., Fewell, J. H., Gadau, J., Johnson, R. A. \& Larrabee, D. Genetic determination of the queen caste in an ant hybrid zone. Proc. Natl Acad. Sci. USA 99, 8157-8160 (2002).

9. Cole, A. C. Pogonomyrmex Harvester Ants; a Study of the Genus in North America (Univ. of Tennessee Press, Knoxville, 1968)

10. Buschinger, A. in Social Insects-an Evolutionary Approach to Castes and Reproduction (ed. Engels, W.) 37-57 (Springer, New York, 1990).

11. Jones, T. R., Routman, E. J., Begun, D. J. \& Collins, J. P. Ancestry of an isolated subspecies of salamander, Ambystoma tigrinum stebbinsi Lowe: The evolutionary significance of hybridization. Mol. Phylogenet. Evol. 4, 194-202 (1995).

12. Welch, M. E. \& Rieseberg, L. H. Patterns of genetic variation suggest a single, ancient origin for the diploid hybrid species Helianthus paradoxus. Evolution 56, 2126-2137 (2002)

13. Xu, S. Phylogenetic analysis under reticulate evolution. Mol. Biol. Evol. 17, 897-907 (2000)

14. Volny, V. P. \& Gordon, D. M. Characterization of polymorphic microsatellite loci in the red harvester ant, Pogonomyrmex barbatus. Mol. Ecol. Notes 2, 302-303 (2002).

15. Bourke, A. F. G., Green, H. A. A. \& Bruford, M. W. Parentage, reproductive skew and queen turnover in a multiple-queen ant analysed with microsatellites. Proc. R. Soc. Lond. B 264, 277-283 (1997).

16. Foitzik, S., Haberl, M., Gadau, J. \& Heinze, J. Mating frequency of Leptothorax nylanderi ant queens determined by microsatellite analysis. Insectes Soc. 44, 219-227 (1997)

17. Taber, S. W. The World of the Harvester Ants (Texas A\&M Univ. Press, College Station, 1998).

18. Parker, J. D. \& Rissing, S. W. Molecular evidence for the origin of workerless social parasites in the ant genus Pogonomyrmex. Evolution 56, 2017-2028 (2002).

19. Simon, C. et al. Evolution, weighting and phylogenetic utility of mitochondrial gene-sequences and a compilation of conserved polymerase chain-reaction primers. Ann. Entomol. Soc. Am. 87, 651-701 (1994).

20. Cavalli-Sforza, L. L. \& Edwards, A. W. F. Phylogenetic analysis: Models and estimation procedures. Evolution 21, 550-570 (1967)

Supplementary Information accompanies the paper on www.nature.com/nature.

Acknowledgements We thank J. Seger for proposing the model presented here; K. Helms, G. Julian and the Student Challenge Awards Project research teams for assistance with field collections; J. Gadau and V. Volny for primer information; and M. Chapuisat, P. Christe, R. Hammond, J. Goudet and J. Parker for feedback on the manuscript. Financial support was provided by grants from the Swiss National Science Foundation to L.K. and the Durfee Foundation to S.H.C

Competing interests statement The authors declare that they have no competing financial interests.

Correspondence and requests for materials should be addressed to S.H.C.

(sara.helmscahan@ie-zea.unil.ch).

\section{Sustained division of the attentional spotlight}

\author{
M. M. Müller, P. Malinowski $\dagger$, T. Gruber ${ }^{\star}$ \& S. A. Hillyard $\ddagger$
}

* Institut für Allgemeine Psychologie, Universität Leipzig, Seeburgstrasse 14-20, 04103 Leipzig, Germany

$\dagger$ School of Psychology, Liverpool John Moores University, 15-21 Webster Street, Liverpool L3 2ET, UK

$\$$ Department of Neurosciences, University of California at San Diego,

9500 Gilman Drive, La Jolla, California 92093-0608, USA

By voluntarily directing attention to a specific region of a visual scene, we can improve our perception of stimuli at that location ${ }^{1}$. This ability to focus attention upon specific zones of the visual field has been described metaphorically as a moveable spotlight or zoom lens that facilitates the processing of stimuli within its 'beam" ${ }^{\prime 2,3}$. A long-standing controversy has centred on the question of whether the spotlight of spatial attention has a unitary beam or whether it can be divided flexibly to disparate locations ${ }^{2,4-6}$. Evidence supporting the unitary spotlight view has come from numerous behavioural ${ }^{3,7-10}$ and electrophysiological ${ }^{11,12}$ studies. Recent experiments, however, indicate that the spotlight of spatial attention may be divided between noncontiguous zones of the visual field for very brief stimulus exposures $(<100 \mathrm{~ms})^{13,14}$. Here we use an electrophysiological measure of attentional allocation (the steady-state visual evoked potential) to show that the spotlight may be divided between spatially separated locations (excluding interposed locations) over more extended time periods. This spotlight division appears to be accomplished at an early stage of visual-cortical processing.

To study whether the beam of spatial attention may be divided over sustained periods of several seconds, we recorded frequencycoded steady-state visual evoked potentials (SSVEPs) to concurrently presented stimuli at attended and interposed unattended locations. The SSVEP is the electrophysiological response of the visual cortex to a rapidly repeating (flickering) stimulus, and generally has a sinusoidal waveform with the same temporal frequency as the driving stimulus ${ }^{15}$. Previous studies have shown that the SSVEP amplitude is substantially increased when attention is focused upon the location of the flickering stimulus ${ }^{16,17}$. The present study recorded SSVEPs to stimuli at four locations, each flickering at a different rate, so that measures of attentional allocation to spatially separated attended locations and interposed unattended locations could be obtained concurrently over periods of several seconds.

Informed consent was obtained from 15 subjects, who viewed the stimuli on a computer monitor while brain activity was recorded non-invasively from 30 scalp electrodes mounted in an elastic cap. During testing, the subject maintained fixation on a central white cross. The stimuli consisted of repetitively flashed white rectangles with superimposed red symbols that were presented at four positions along the horizontal meridian (Fig. 1). On each trial the rectangles were flashed continuously for 3.06 seconds at $15.2 \mathrm{~Hz}$ (position 1), $8.7 \mathrm{~Hz}$ (position 2), $20.3 \mathrm{~Hz}$ (position 3) and $12.2 \mathrm{~Hz}$ (position 4). Randomized sequences of five different symbols were presented at each location. Symbol presentations occurred in synchrony at the four locations with fixed durations of $181 \mathrm{~ms}$.

The subject's task was to pay attention to the symbol sequences at two of the four positions, and to push a button upon detecting the simultaneous occurrence of a particular target symbol at those two positions. On separate blocks of trials, subjects were instructed verbally to attend to either the two left field positions $(1+2)$, the two right field positions $(3+4)$, or to two separated positions $(1+3)$ or $(2+4)$. Simultaneous target symbols occurred unpre- 